
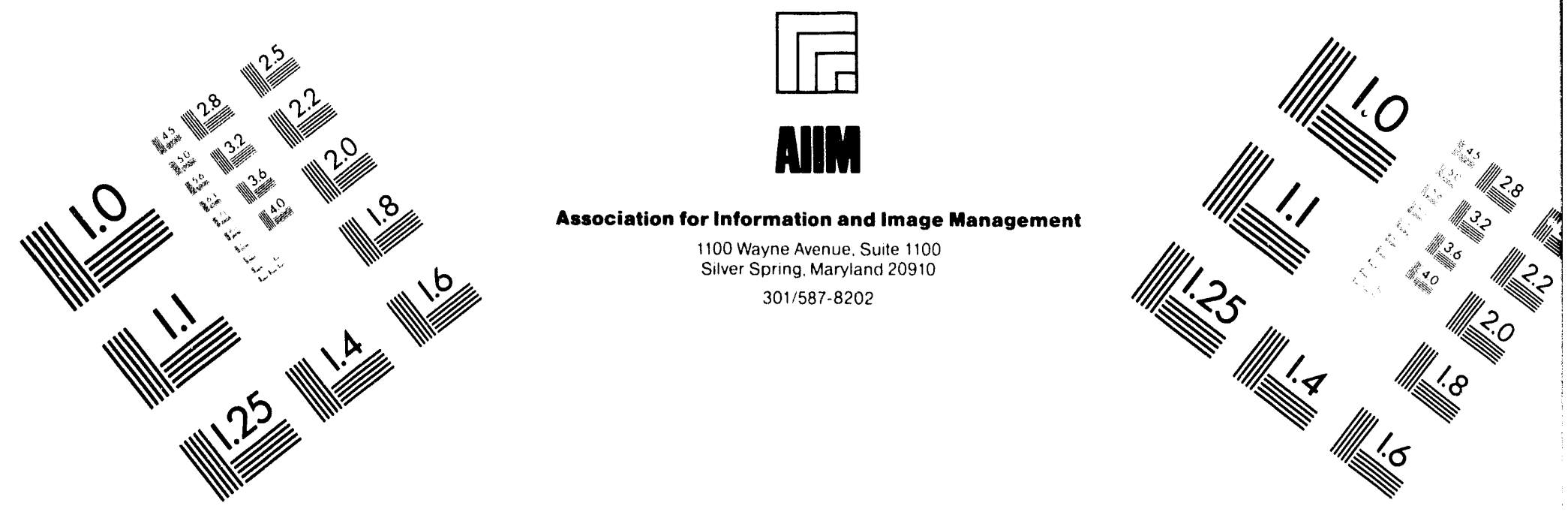

\title{
Centimeter
}

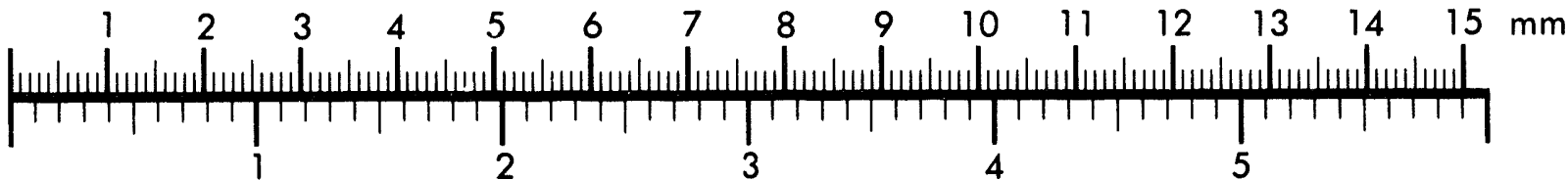
Inches
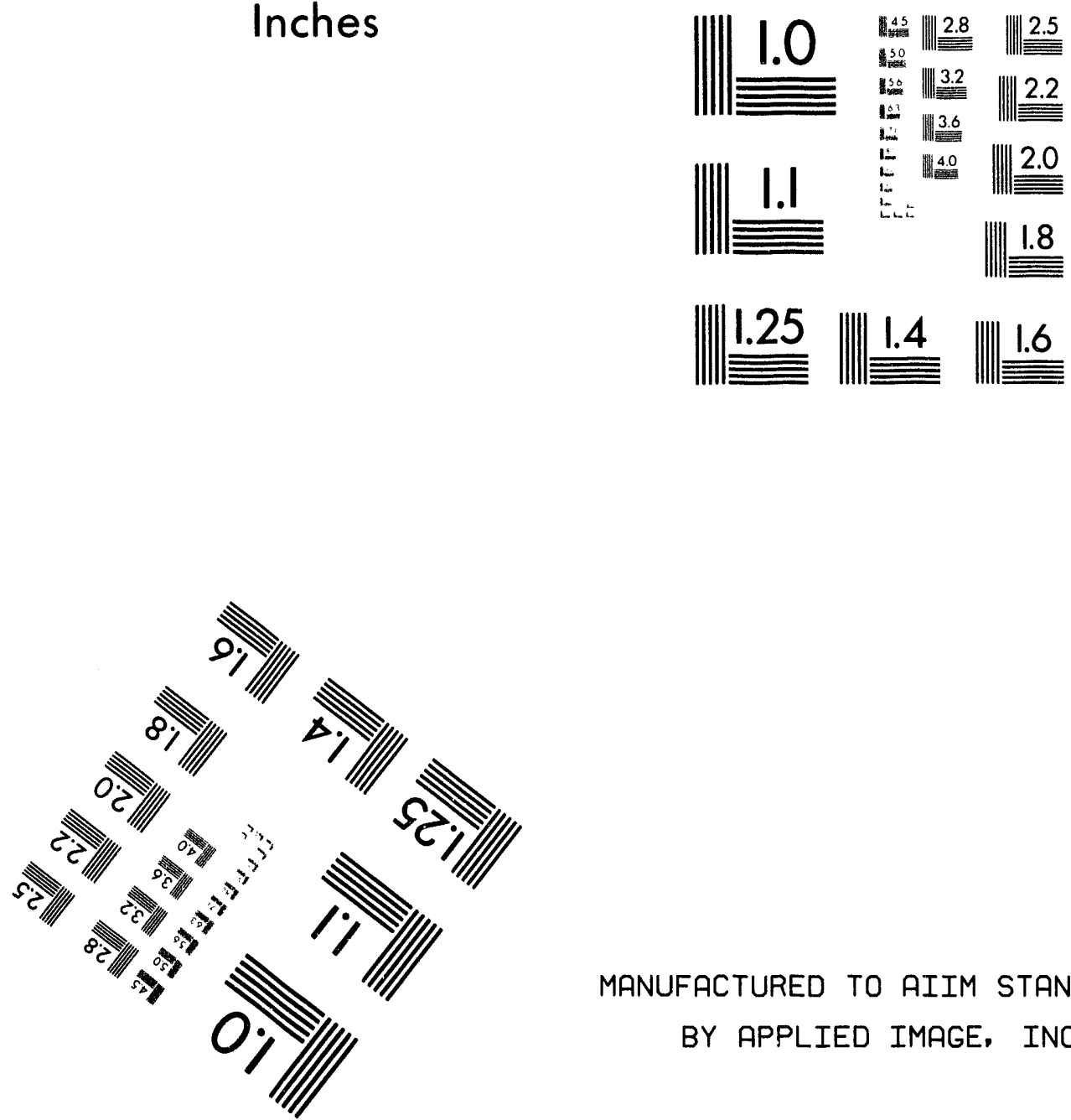

MANUFACTURED TO AIIM STANDARDS

BY APPLIED IMAGE, INC.

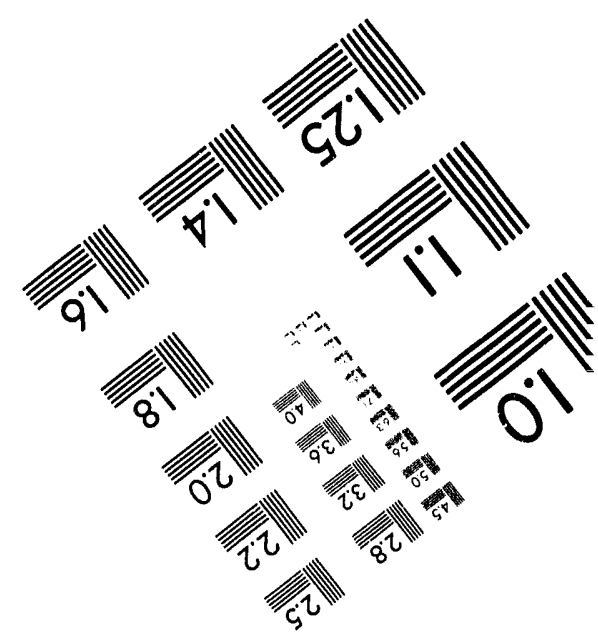



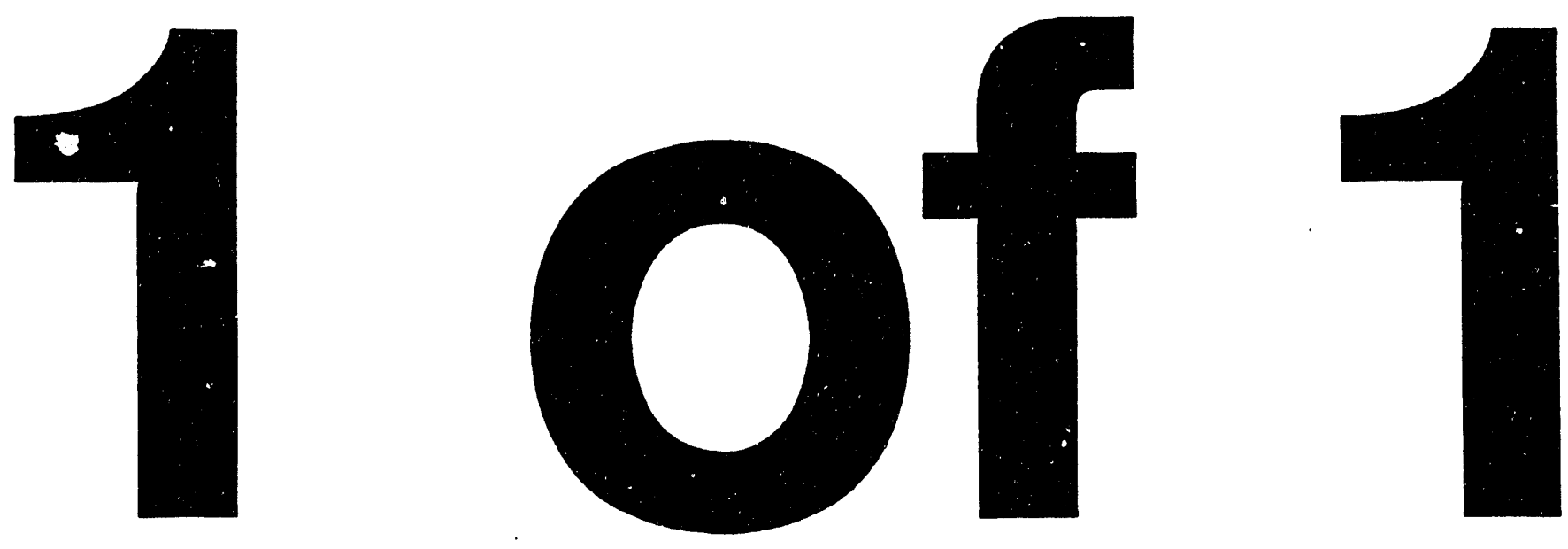
$x \operatorname{yen}^{9}+4123142$

ANL/PAM/PP- $-276 \%$

\section{DYMAMIC LIGHT SCATTERING INVESTIGATIONS OF A NEW CLASS \\ OF POLYETHYLENEIMINE DERIVATIVES}

Donna M. Budzynski ${ }^{1}$, Elizabeth $\cdot A$. Myatt ${ }^{2}$, and Albert S. Benight ${ }^{1+}$

1. Department of Chemistry, mc/111, University of Illinois at Chicago, Box 4348, Chicago, Illinois 60680

2. Biological and Medical Research Division, Argonne National Laboratory 9700 South Cass Avenue, Argonne, Illinois 60439

\section{DISCLAIMER}

This report was prepared as an account of work sponsored by an agency of the United States Government. Neither the United States Government nor any agency thereof, nor any of their employees, makes any warranty, express or implied, or assumes any legal liability or responsibility for the accuracy, completeness, or usefulness of any information, apparatus, product, or process disclosed, or represents that its use would not infringe privately owned rights. Reference i:erein to any specific commercial product, process, or service by trade name, trademark, manufacturer, or otherwise does not necessarily constitute or imply its endorsement, recommendation, or favoring by the United States Government or any agency thereof. The views and opinions of authors expressed herein do not necessarily state or reflect those of the United States Government or any agency thereof.

DISTRIBUTION OF THIS DOCUMENT IS UNLIMITED

+ To Whom Correspondence Should be Addressed

y 
Summary: Dynamic light scattering measurements were performed on polyethyleneimine and several chemically modified derivatives that differ in the placement site, degree of substitution, and chemical nature of alkyl substituents. Moreover, two of the six polymer derivatives were acetylated for amine charge neutralization. Dynamic light scattering results indicate that the unmodified polymers assume the most extended and probably most highly aggregated structure in aqueous solution $(100 \mathrm{mM} \mathrm{Tris}-\mathrm{HCl}, \mathrm{pH}=6.8)$. Attachment of decyl groups on the primary amines has little effect on the solution properties of the polyethyleneimine polymers; these modified polymers are most similar to the unmodified polymers. In contrast, attachment of dodecyl or dodecylbenzyl groups on the tertiary amines induces the polymers to contract. In addition these polymers do not seem to aggregate as extensively as the unmodified polymers. Results demonstrate the utility of dynamic light scattering measurements to provide novel insight into effects of relative hydrophobicity of polyethyleneimine polymers on their extension and aggregation tendencies in aqueous solution. These results may provide a basis for understanding the enzymatic properties of polyethyleneimine polymers.

Over the past 25 years, polymers of polyethyleneimine (PEI) and its derivatives have proven to be an interesting class of synthetic macromolecular catalysts (1-5). With them, significant rate enhancements have been achieved in the esterolysis of phenyl esters (1), aryl phosphate esters (2) and nitrophenyl sulfate esters (3) as well as in other reactions including oxaloacetate decarboxylation. (4) and disulfide cleavage (5). These catalytic activities make modified PEI polymers attractive candidates for synthetic enzyme development. The choice of PEI in early experiments was based on the presumption that the polymer's branched structure would result in a compact globular tertiary structure (6). Because the ratio of primary to secondary to tertiary amine in PEI is $1: 2: 1$ (7), the potential formation of branched, extended and associated intermolecular structures is seemingly large. However, experimental evidence regarding this conjecture is sparse. In fact, little is known about the hydrodynamic properties of PEI other than its considerably low intrinsic viscosity (7).

In this communication, we report dynamic light scattering (DLS) investigations of unmodified PEI polymers and derivatives that contain various modifications of the primary, secondary and tertiary amines. These measurements performed in an aqueous solvent $(100 \mathrm{mM} \mathrm{Tris-HCl,} \mathrm{pH}=6.8)$ provide semi-quantitative insight "into the effects of novel amine modifications on the shape and extension of PEI polymers in solution. 


\section{MATERIALS AND METHODS}

PEI Samples

The fundamental subunit of unmodified PEI is shown in Figure 1 . The sample of unmodified PEI polymers that served as the precursor to the modified polymers, was purchased from Dow Chemical, Midland, MI. The reported molecular weight of these polymers, $M_{r} \approx 50,000$ indicates they contain approximately 1165 fundamental subunits. The novel synthetic protocols employed to construct the modified PEI polymers of this study were recently published (9). Locations of the primary $\left(1^{\circ}\right)$, secondary $\left(2^{\circ}\right)$ and tertiary $\left(3^{\circ}\right)$ amines and the modifications that were made at these positions are indicated in Figure 1. A second sample of unmodified PEI $\left(M_{r}=50,000\right)$ was purchased from Sigma (St. Louis, MO) and also examined.

The two unmodified and five modified PEI polymers that were examined are listed in Table 1. Henceforth, these polymers are designated A-G. The amine positions and extent of modification of each polymer are given in Table 1. A and B are unmodified polymers from different sources. Sample A was vacuum dried and rehydrated before measurements, while Sample B was obtained in liquid form, diluted and used directly without further treatment. Sample $C$ is acetyl PEI i.e. the water soluble analog of the triflouroacetyl compound used in synthesis $(9,10)$. In sample $D, 10 \%$ of the total number of amines have been decylated; substitution occurs on the primary (terminal) amines. Sample $E$ has $4 \%$ of the total amines dodecylated, all being of the tertiary type. In sample $F 25 \%$ of the amines have been dodecylated, again at branchpoints (i.e. tertiary amine sites). Finally, sample $G$, the most extensively modified polymer, has primary amines completely methylated, $60 \%$ of the secondary amines permethylated, and the remaining $40 \%$ containing both a methyl group and a $2-\mathrm{OH}$ propyl group. Also in sample G, $90 \%$ of the tertiary amines have been quaternized with dodecylbenzyl groups. The remaining $10 \%$ of the tertiary amines in sample $G$ should, in principle, be methylated. The extent of each type of modification was determined by $\mathrm{C}-13$ and proton NMR spectra of each polymer (9). $M_{r}$ estimates of the modified polymers are listed in Table 1. Following their synthesis and purification, modified polymers and their unmodified precursor were exhaustively dialyzed; first versus $100 \mathrm{mM} \mathrm{NaCl}$ then against double distilled $\mathrm{H}_{2} \mathrm{O}$, lyophilized and stored at $-20^{\circ} \mathrm{C}$.

Dynamic Light Scattering (DLS) Measurements

For DLS measurements, PEI samples were dissolved to a final concentration of approximately $3.0 \mathrm{mg} / \mathrm{ml}$ (determined by analytical weighing) in $100 \mathrm{mM}$ Tris-HCl, $\mathrm{pH}=6.8$. Samples were filtered under slight syringe pressure through $0.45 \mu \mathrm{m}$ polysulphone filters (Gelman Sciences, Ann Arbor, MI) into a cylindrical scattering cell that had been pre-washed with filtered buffer. Initial DLS measurements were made on the samples as a function of time. Before the $\mathrm{fl}_{\mathrm{l}} 1$ set of DLS measurements were made, the dissolved polymer solutions were allowed to equilibrate until measurements did not change. Generally, equilibration required at least 92 hours at $4^{\circ} \mathrm{C}$.

Detailed descriptions of our DLS apparatus and methods of data analys is have been published (11-13). Briefly, intensity autocorrelation functions, $G^{(2)}(K, t)$, were collected at scattering angles, $\theta$, in $10^{\circ}$ increments from $30^{\circ}$ to $130^{\circ}$. This angular range corresponds to values of the square of the scattering vector, $K^{2}$, from 1.56 to $19.6 \times 10^{10} \mathrm{~cm}^{-2} . K=\left(4 \pi \mathrm{n} / \lambda_{0}\right) \sin (\theta / 2)$, where $\lambda_{0}$ is the wavelength of the incident light in vacuo $(351.1 \mathrm{~nm})$, and $n$ 
$=1.348$ is the refractive index of the solvent.

The first order normalized field correlation function, $g^{(1)}(K, t)$, is obtained from $G(2)(K, t)$ and the correlation function baseline, $B$, and then expressed as a sum of exponentials, viz.

$$
g^{(1)}(K, t)=\left[\left(G^{(2)}(K, t)-8\right) / B\right]^{0.5}=\sum_{1} a_{1} \exp \left(\Gamma_{i} t\right)
$$

$g^{(1)}(K, t)$ is subjected to Laplace inversion using the program CONTIN (14). Inversion analysis provided distribution functions of the relaxing components present in each PEI solution. Based on the number of predominant components suggested by the distribution function, exponential fits of $g^{(1)}(K, t)$ using the amplitudes, $a_{i}$, and decay rates, $\Gamma_{i}$, as adjustable in the fits were made at all angles. From the evaluated decay rates at a particular $K^{2}$ or $\theta$, the diffusion coefficients, $D_{i}=\Gamma_{i} / K^{2}$ were calculated. DLS measurements were collected at $22^{\circ} \mathrm{C}$.

\section{RESULTS}

Representative distribution functions of diffusion coefficients, viscosity and temperature corrected to that of water at $20^{\circ} \mathrm{C}\left(\mathrm{D}_{20}\right)$ obtained from analysis of DLS data collected on PEI polymers $A$ and $E$ of Figure 1 , are shown for comparison in Figure 2. As indicated, the top panels are the distributions obtained at $\theta=30^{\circ}$ and those shown in the lower panels were obtained at $\theta=130^{\circ}$. These particular distribution functions are shown because they represent the extremes in behavior displayed by all the PEI polymers investigated in this study. Also, since 30 and $130^{\circ}$ were the lowest and highest scattering angles examined, the contrast between the distributions in the upper and lower panels reveals the range of the angular dependent variations of the features of the distributions. The distributions in Figure 2 bracket the analogous distributions obtained for the other PEI samples at these and intermediate angles (not shown).

The solid lines in Figure 2 are the distributions obtained by Laplace inversion; the arrows depict positions and amplitudes of the relaxing components obtained from tri-exponential fits of the same data. The complexity of the distribution functions in Figure 2 reveal the apparent heterogeneity of the PEI solutions. At first site this polydispersity makes it difficult to make unequivocal assignment of all the peaks to specific molecular species of the PEI polymers or dynamical processes (motions) occurring within them. However, relying on our previous experience from DLS studies of aggregating protein and DNA systems that display similar multiple peaked distributions $(12,13)$, an explanation of the relatively lower 
amplitude components on the wings of the distribution functions can be given. For instance, the extremely low amplitude fast peak observed at the far right on three of the four distributions displayed in figure $2\left(\mathrm{D}_{20}>\right.$ $\left.100 \times 10^{-8} \mathrm{~cm}^{2} / \mathrm{s}\right)$ is so fast that it decays in only the first channel of the correlation function. Assignment and comparison of this component is therefore not possible. Likewise, the slowest component $\left(D_{20} \leq 1.5 \times 10^{-8}\right.$ $\mathrm{cm}^{2} / \mathrm{s}$ ) also has a fairly low amplitude and occurs in the baseline region at channel 256 of the correlation function. We have previously observed such slow peaks in similarly analyzed DLS data collected on aggregating proteins $(12,13)$. In those studies this component was attributed to a small population of extremely large particles and/or dust in the sample. Because it has such a small relative amplitude $(-0.05)$ it can easily be removed by conservative adjustmerics of the baseline. The significantly lower relative amplitudes and poor resolution of these extreme components compromises them as a reliable bases for relative comparisons. Therefore, the behavior of the intermediate main components, hereafter referred to as 1 and 2 , are used to compare the DLS results of the PEI polymers shown in Figure 1.

The diffusion coefficients corresponding to the main components of the distribution function obtained for each of the PEI polymers shown in Figure 1 are listed in Table 1 . These values, $D_{1}$ and $D_{2}$, were determined by linearly extrapolating the values of $\mathrm{D}_{20}$ of each component obtained over the entire range to $K^{2}=0 . D_{1}$ and $D_{2}$ determined in this manner are necessarily translational diffusion coefficients of the molecular center of mass of components of the PEI polymers. From these diffusion coefficients, $D_{0}=D_{1}$ or $D_{2}$, the hydrodynamic radius, $R_{H}=k_{B} T / 6 \pi \eta D_{0}$, was evaluated, where $k_{B}, T$ and $\eta$ are the Boltzmann constant, the absolute temperature and solvent viscosity, respectively. The hydrodynamic radii determined in this way for the fast components (component 2) of the PEI polymers are listed in Table 1.

In order to ascertain some estimate of the relative extension (or aggregation state) of the PEI polymers, the radius of a non-hydrated hard sphere corresponding to the assumed $M_{r}$ of each polymer (see Table 1) was calculated using a density of $1.00 \mathrm{~g} / \mathrm{ml}$. The radii obtained from these estimates necessarily provide an absolute lower limit on the actual size of the polymers since they are likely to be non-spherical and hydrated. The ratios of the experimentally determined hydrodynamic radius to the hard- 
sphere radius for component $2, R_{H}(2) / R_{S}$, are 1 isted for each polymer in Table 1. The smaller the $R_{H}(2) / R_{s}$ ratio, the more compact shape the polymers assume. These ratios range from 5 to 6 for the unmodified PEI polymers ( $A$ and $B$ ) and the polymer with only primary amines modified (D) down to approximately 2 for acetylated PEI $(C)$ and the PEI polymers that have some degree of hydrophobic modification of their tertiary amines ( $E$, $F)$. The $R_{H}(2) / R_{S}$ ratio of the most modified polymer $(G)$, is also 2 . The results on polymers $E, F$ and $G$ demonstrate that modification of the tertiary amines has a larger effect on the hydrodynamic shape of PEI polymers than does placement on primary amines. Surprisingly, quaternization of tertiary amines with a hydrophobe did not result in polymer expansion. Acetylation also reduces the hydrodynamic radius. For comparison, based on sedimentation experiments, globular proteins of comparable $M_{r}$ 's have $R_{H} / R_{s}$ ratios between 1.14 and 1.35 (15), while more extended proteins of similar $M_{r}$ have $R_{H} / R_{s}-3$.

Fluorescence measurements have indicated aggregation in solutions of PEI (16). From Table 1 we see the $D_{1}$ values for the PEI samples are lower than the $D_{2}$ values suggesting $D_{1}$ corresponds to a more highly aggregated state of the polymers. The larger $R_{H} / R_{s}$ ratios and lower $D_{1}$ values obtained for polymers $A, B$ and $D$ therefore suggest these molecules that diffuse more slowly are probably considerably more extended and tend to aggregate to a greater extent than polymers C, E, F, and G. These aggregates cannot result from hydrogen bonding alone as previously suggested (17) because the aggregates are formed even in perquaternary PEI, polymer G. Apparently, attachment of hydrophobic moieties on the tertiary amines of PEI polymers induces them to contract and lowers their tendency to aggregate.

\section{ACKNOWLEDGEMENTS}

We acknowledge Dr. David $H$. Wilson for collecting some of the dynamic light scattering data in early stages of this work. This work was supported by N.S.F. grant DMB-9018782 (A.S.B.). 


\section{REFERENCES}

1. Klotz, I., Royer, G. and Scarpa, I. (1971) Proc. Nat1. Acad. Sci. (USA) $68,263-264$.

2. Scarpa, I., Kiefer, H. and Klotz, I. (1973) Intra-Science Rept. 8, $450-454$.

3. Keifer, H., Congdon, W., Scarpa, I. and Klotz, I. (1972) Proc. Natl. Acad. Sci. (USA) 69, 2155-2159.

4. Kitano, H., Hishiki, S., Mayana, A. and Ise, N. (1983) Macromolecules $16,539-542$.

5. Weatherhead, R., Stacey, K. and Williams, A.J. (1978) J. Chem. Soc., Perkin Trans. II, 800-807.

6. Davis, L.E. (1968) Water Soluble Resins, Reinhold, New York, p.216.

7. Klotz, I. (1977) Adv. Chem. Physics 39, 109-176.

8. Mirejovsky, D. (1979) J. Org. Chem. 44, 4881-4886.

9. Myatt, E. and Scarpa, I. (1990) Bioorganic Chemistry 18, 413-424.

10. Johnson, T.W., Klotz, I.M. (1974) Macromolecules 7, 149-153.

11. Wilson, D.H., Price, H.L., Henderson, J., Hanlon, S. and Benight, A. S. (1990) Biopolymers 29, 357-376.

12. Benight, A.S., Wilson, D.H., Budzynski, D.M. and Goldstein, R.F. (1991) Biochimie 73, 143-155.

13. Budzynski, D.M., Benight, A.S., LaBrake, C.C. and Fung, L.W.-M. (1992) Biochemistry 31, 3653-3660.

14. Provencher, S. W. (1982) Comput. Phys. Commun. 27, 213-229.

15. Tanford, C. (1967) Physical Chemistry of Macromolecules, Wiley, New York, p.358.

16. Parker, C.A. and Joyce, T.A. (1974) J. Appl. Polym. Sci. 18, 155-165.

17. Thiele, X. and Gronau, Y. (1963) Makrmol. Chem. 59, 207-221.

\section{FIGURE CAPTIONS}

Figure 1: Fundamental Subunit of the Modified PEI Polymers of this Study. $A$ and $B$ are the unmodified PEI. C-G indicate the positions and identity of modification of the PEI polymers as described in the text and summarized in Table 1 .

Figure 2: Distribution Functions of PEI Polymer Components. Normalized amplitude versus diffusion coefficient at $20^{\circ} \mathrm{C}, \mathrm{D}_{20}$, obtained by Laplace inversion (solid lines and symbols) of dynamic light scattering data collected at scattering angles, $\theta=30$ and $130^{\circ}$, for PEI polymers $A$ and $E$ shown in Figure 1 and Table 1. The arrows indicate the amplitudes and positions of relaxing components 1 and 2 obtained by fitting the same dynamic light scattering data with a tri-exponential function. These data represent the extremes in the behavior observed for different classes of PEI polymers investigated. 


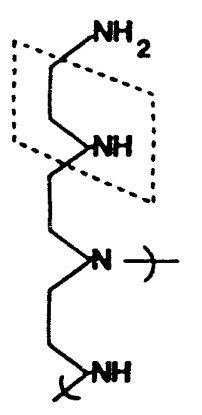

A,B

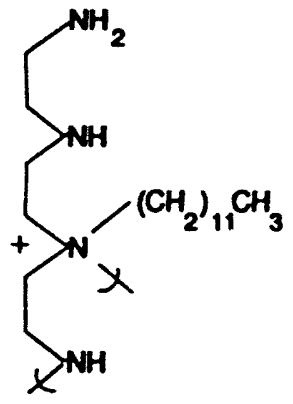

E

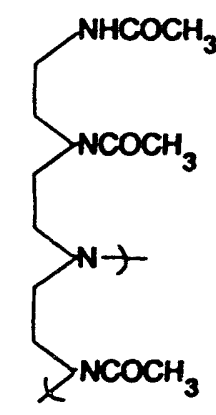

C

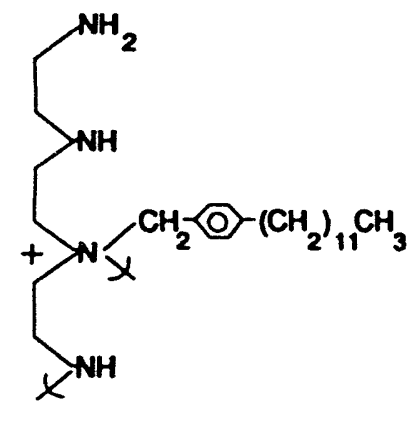

F

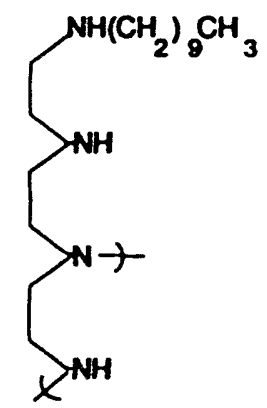

D

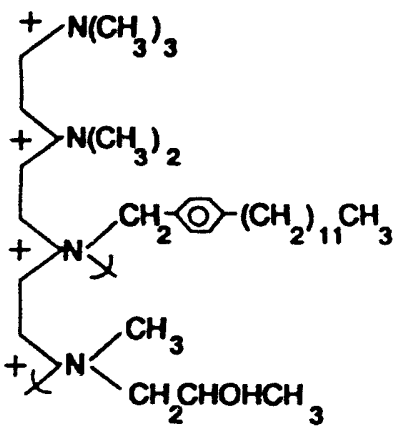

G 

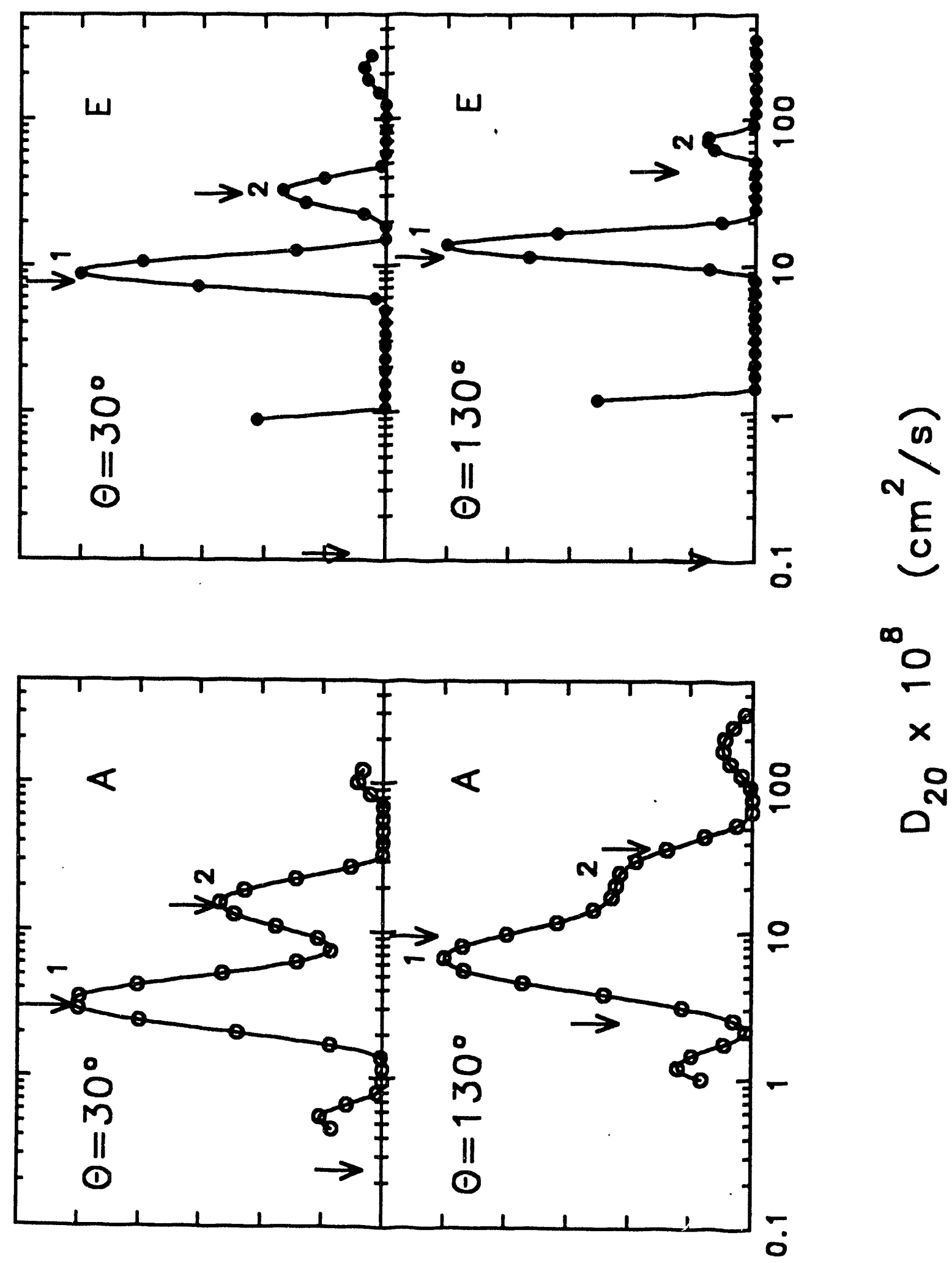

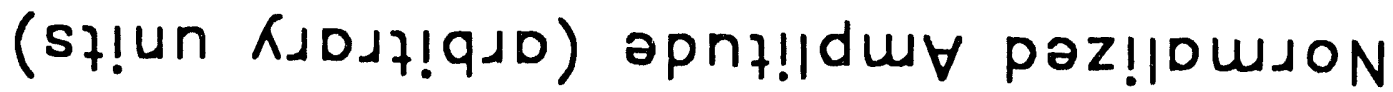


TABLE 1: Summary of Dynamic Light Scattering Measurements of Polyethyleneimine Polymers

\begin{tabular}{|c|c|c|c|c|c|c|c|}
\hline & MODIFICATION ${ }^{1}$ & $\begin{array}{l}\text { MW } \\
\left(10^{3}\right)\end{array}$ & $\begin{array}{r}R_{S} \\
\AA^{\prime} \\
\pm \quad 2\end{array}$ & $\begin{array}{c}D_{1} \\
\times \quad 10^{8} \\
\left(\mathrm{~cm}^{2} / \mathrm{s}\right)\end{array}$ & $\begin{array}{c}\mathrm{D}_{2} \\
\times \quad 10^{8} \\
\left(\mathrm{~cm}^{2} / \mathrm{s}\right)\end{array}$ & $\begin{array}{c}R_{H}(2) \\
\AA \\
\pm \quad 3\end{array}$ & $R_{H}(2) / R_{S}$ \\
\hline A & unmodified & 50 & 27 & 3.3 & 13.1 & 164 & $6.1 \pm .5$ \\
\hline B & $\begin{array}{l}\text { unmodified } \\
\text { not dried }\end{array}$ & 50 & 27 & 4.7 & 16.4 & 131 & $4.9 \pm .4$ \\
\hline C & acetyl PEI & 99 & 34 & 7.0 & 27.8 & 77 & $2.3 \pm .2$ \\
\hline D & $10 \%$ decy $11^{\circ}$ & 67 & 30 & 2.7 & 16.3 & 131 & $4.4 \pm .4$ \\
\hline $\mathbf{E}$ & $4 \%$ dodecyl $3^{\circ}$ & 58 & 28 & 9.5 & 31.7 & 68 & $2.4 \pm .3$ \\
\hline $\mathbf{F}$ & $\begin{array}{l}25 \% \text { dodecyl- } \\
\text { benzy } 3^{\circ}\end{array}$ & 125 & 37 & 15.4 & 29.3 & 73 & $2.0 \pm .2$ \\
\hline G & see below" & 166 & 40 & 5.9 & 23.7 & 90 & $2.3 \pm .2$ \\
\hline
\end{tabular}

${ }^{1}$ Modification expressed as a percentage of the total amine.

\section{MODIFICATION OF DERIVATIVE G:" .}

\begin{tabular}{|c|c|c|}
\hline $1^{\circ}$ amine & $2^{\circ}$ amine & $3^{\circ}$ amine \\
\hline $300 \%$ methyl & $\begin{array}{c}160 \% \text { methyl } \\
40 \% 2-0 \mathrm{O} \text { propyl }\end{array}$ & $\begin{array}{c}10 \% \text { methyl } \\
\text { 200\% dodecyl benzyl }\end{array}$ \\
\hline
\end{tabular}

"Modification expressed as a percentage of the amine type listed, assuming a $1^{\circ}: 2^{\circ}: 3^{\circ}$ ratio of $0.25: 0.50: 0.25$. 

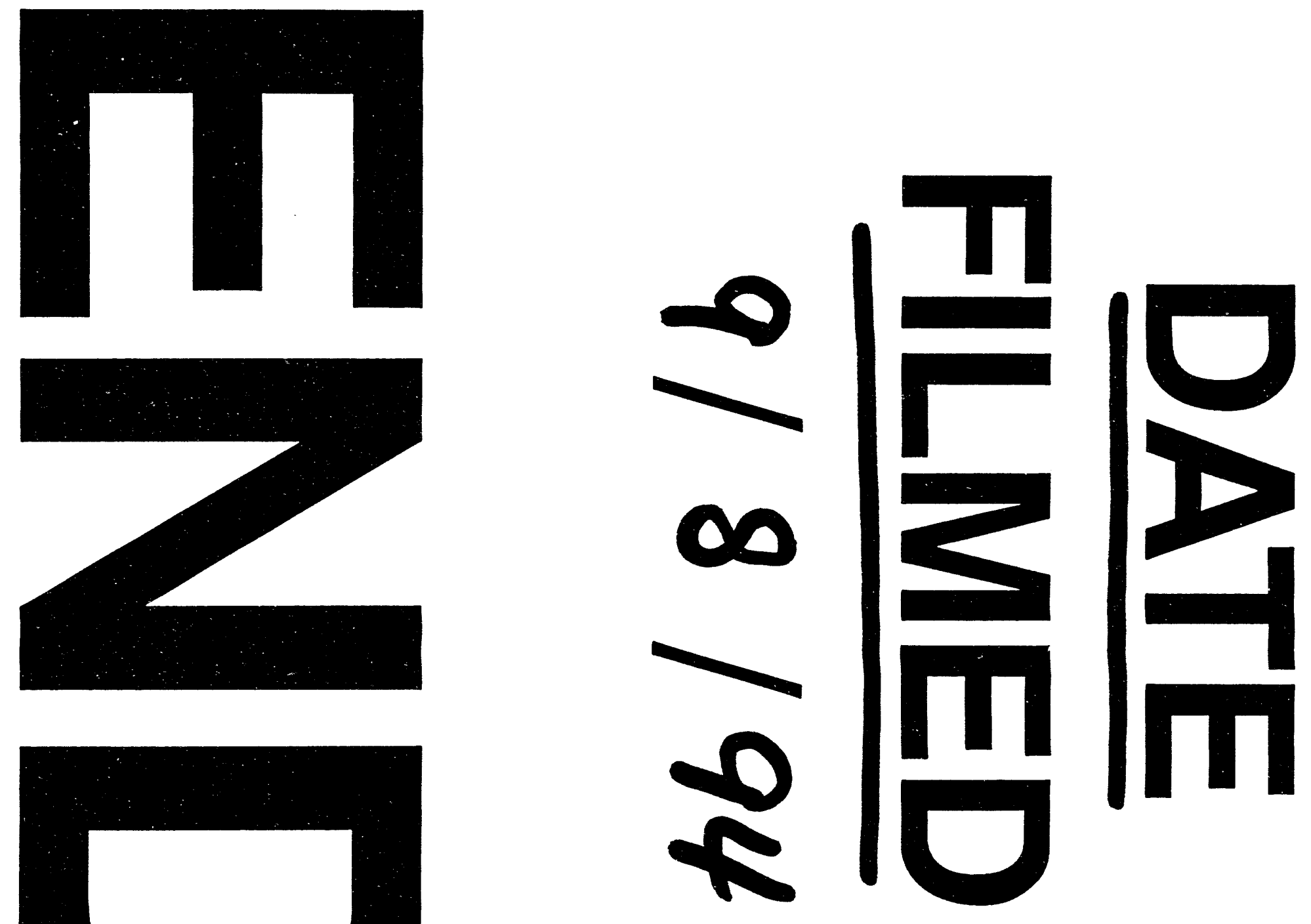